\title{
Understanding and Treating Procrastination: A Review of a Common Self-Regulatory Failure
}

\author{
Alexander Rozental*, Per Carlbring \\ Division of Clinical Psychology, Department of Psychology, Stockholm University, Stockholm, Sweden \\ Email: ${ }^{\text {alexander.rozental@psychology.su.se }}$
}

Received 4 July 2014; revised 1 August 2014; accepted 25 August 2014

Copyright (C) 2014 by authors and Scientific Research Publishing Inc.

This work is licensed under the Creative Commons Attribution International License (CC BY). http://creativecommons.org/licenses/by/4.0/

(c) (7) Open Access

\begin{abstract}
Procrastination is a pervasive self-regulatory failure affecting approximately one-fifth of the adult population and half of the student population. It is defined as one's voluntarily delay of an intended course of action despite being worse off as a result of that delay. Procrastination has a negative impact on performance and is associated with poorer mental health. Stress, worry, and feelings of guilt are common among those who procrastinate recurrently. In addition, procrastination is associated with fewer mental health-seeking behaviors and increased treatment delay, leading to greater distress and the exacerbation of illness. The current paper seeks to provide a theoretical and clinical understanding of procrastination by reviewing prior research. Procrastination can be understood using different motivational theories, learning theory, self-efficacy theory, as well as biases and heuristics. Temporal motivational theory is proposed as an integrated explanation for procrastination, consisting of the interaction of four different variables: expectancy, value, impulsiveness, and time, each of which affects the tendency to procrastinate. A general implication is that procrastination should be regarded as an idiosyncratic behavioral problem that requires a cognitive case conceptualization or a functional analysis in order to guide therapists in their work. A number of treatment interventions might be used in relation to procrastination-for example, efficacy performance spirals, automaticity, stimulus control, stimulus cues, learned industriousness, and cognitive restructuring. Furthermore, the current paper explores the evidence on using cognitive behavior therapy for procrastination, discussing the scarcity of randomized controlled trials and the lack of validated outcome measures, and highlighting the need for further research.
\end{abstract}

\section{Keywords}

Procrastination, Cognitive Behavior Therapy, Review

\footnotetext{
${ }^{*}$ Corresponding author.
} 


\section{Introduction}

Every once in a while people postpone the tasks and assignments they are supposed to perform. Although this is often experienced as stressful, delaying a given course of action seldom results in any major psychological suffering. However, for some individuals, deferring what needs to be done can become a persistent behavioral pattern that interferes with daily life. Referred to as procrastination - that is, voluntarily delaying an intended course of action despite the negative consequences of that delay (Klingsieck, 2013)—-this behavior involves the postponement of initiating or completing a commitment until the last minute, until after a predetermined deadline, or indefinitely (Dryden, 2000). Though similar to the difficulties that some individuals face when having to prioritize or being self-assertive, procrastination requires an active choice between competing activities in which one is avoided in favor of the other and is usually characterized by the preference for an immediate reward or the escape from a potentially aversive experience (Dryden, 2000). Procrastination is not only associated with negative consequences for the activity being delayed but is also related to decreased well-being, poorer mental health, lower performance, and financial difficulties (Sirios, 2007; Stead, Shanahan, \& Neufeld, 2010; Tice \& Baumeister, 1997; O’Donoghue \& Rabin, 1999). In addition, deferring wellness behaviors can often result in treatment delay, a lack of compliance, and the exacerbation of distress, most notably with reference to physical illness (Sirios, 2004).

Even though procrastination can contribute to many adversities among those afflicted, research concerning treatment interventions is currently scarce (Pychyl \& Flett, 2012). Procrastination has mainly been explored from the perspective of possible predictors and mediators, such as personality factors, task characteristics, and sociodemographics (Steel, 2007). Although valuable in order to understand the phenomenon's underlying mechanisms, this approach has also limited the scope of the research. In terms of clinical trials investigating different treatment interventions, there is insufficient knowledge regarding their usefulness (Rozental \& Carlbring, 2013). The research also lacks validated outcome measures, randomization, and long-term follow-ups, complicating the results. Treatment interventions stemming from cognitive behavior therapy (CBT) are often considered suitable for addressing problems of procrastination-interventions such as stimulus cues, time management, goal-setting techniques, learned industriousness, automaticity, stimulus control, modeling, performance accomplishments, implementation intentions, success spirals, and fusing (Steel, 2007)_but the evidence for their efficacy is still unclear (Pychyl \& Flett, 2012). Further research is therefore warranted in order to comprehend what mediates treatment outcome and facilitate treatment interventions that specifically target procrastination.

The primary aim of the current paper is to review research on procrastination to guide therapists when treating individuals suffering from problems associated with delaying their everyday commitments. Understanding the underlying mechanisms responsible for procrastination could help therapists identify maintaining factors, in turn affecting the choice of treatment interventions. Furthermore, this paper also intends to aid researchers in conducting clinical trials on procrastination, particularly in terms of study design and the use of validated outcome measures. Earlier research of CBT for procrastination is examined, focusing on the main results as well as the studies' limitations, highlighting some of the issues that must be considered when investigating the efficacy of treatment interventions for procrastination.

\section{Understanding Procrastination}

\subsection{Definition}

Procrastination can be defined in a number of ways depending on which aspect of the behavior is being emphasized (Klingsieck, 2013)_for example, distress ("procrastination is delay in conjunction with subjective discomfort”; Solomon \& Rothblum, 1984), postponement ("procrastination is when we delay beginning or completing an intended course of action”; Beswick \& Mann, 1994), and irrationality ("procrastination is the illogical delay of behavior"; Sabini \& Silver, 1982). Consequently, there exist several definitions of procrastination in the research that could be regarded as either contradictory or complementary (van Eerde, 2000). A broader definition that incorporates different aspects of the same behavior might be more useful in distinguishing procrastination from other related activities (e.g., a lack of self-assertiveness). Steel (2007) therefore suggests using this definition: "to voluntarily delay an intended course of action despite expecting to be worse-off for the delay," which highlights the main components of procrastination in one uniform definition. However, because procras- 
tination is not considered a psychiatric condition, determining its occurrence is complicated, precluding the use of diagnostic criteria or a structured clinical interview (Rozental \& Carlbring, 2013). Probing whether the behavior results in subjective discomfort is thus important and should always be considered when consulting individuals regarding their procrastinatory problems; distress may be manifested as, for instance, interpersonal problems, physical illness, stress, anxiety, depression, and financial difficulties.

\subsection{Prevalence}

Measures of the prevalence of procrastination are exclusively based on self-report measures, which indicate that approximately 15\% - 20\% of the adult population (Harriott \& Ferrari, 1996) and 50\% of the student population (Day, Mensink, \& O'Sullivan, 2000) perceive themselves as engaging in procrastination to the extent that it causes personal distress or difficulties. However, using self-reports has several drawbacks, particularly in terms of differentiating severe and chronic procrastination from more trivial cases of deferring tasks and assignments. In addition, the different definitions of procrastination that exist could also explain the large variation in prevalence that is found in the research (Steel, 2007). The number of individuals actually suffering from procrastination may therefore be lower, warranting further research on the phenomenon's prevalence using additional information in order to increase the validity of the results (e.g., behavioral assessments and validated outcome measures).

\subsection{Sociodemographics}

Research on procrastination has mainly involved the investigation of the underlying mechanisms that could affect one's tendency to delay a given course of action, particularly sociodemographics (Steel, 2007). Findings suggest a small influence of gender, whereby men procrastinate slightly more than women do, revealing a weak negative correlation between the female gender and procrastination $(r=-.08)$, possibly related to greater selfcontrol among women in general (van Eerde, 2003; Else-Quest, Hyde, Goldsmith, \& van Hulle, 2006). Age, on the other hand, is associated with less procrastination $(r=-.15)$, and results correcting for range restrictions indicate an even larger correlation $(r=-.48)$ (Steel, 2007). The relation with age might owe to the development of higher cognitive functions during adolescence that are essential for self-regulation and goal setting, explaining the greater number of self-reported procrastinators in the student population (O'Donoghue \& Rabin, 1999; Banich, 2009). Furthermore, according to socioemotional selectivity theory, people's perception of time per se changes with age and the experience of mortality: time is perceived as more abstract during childhood and becomes increasingly concrete with older age (Carstensen, Isaacowitz, \& Charles, 1999). To put it differently, when time is running out, there is no room left for postponing the commitments that need to be done, resulting in less procrastination.

\subsection{Personality Traits}

In addition to sociodemographics, personality traits have been researched extensively in relation to procrastination, most notably using personality inventories such as the big five taxonomy (van Eerde, 2003). Results demonstrate only weak correlations between procrastination and openness to experience $(r=.03)$, agreeableness $(r=$ $-.12)$, and extraversion $(r=-.12)$ but a small correlation with neuroticism $(r=.24)$, and a large correlation with conscientiousness $(r=-.62)$ (Steel, 2007). Neuroticism involves the tendency to experience feelings of anxiety and depression, as well as to be more self-conscious and worrisome, which could explain the relation with procrastination (Hettema, Neale, Myers, Prescott, \& Kendler 2006). Conscientiousness is, on the other hand, defined as being careful, thorough, and tenacious—qualities that most likely would limit the tendency to procrastinate (Ozer \& Benet-Martinéz, 2006). However, as proposed by Steel (2007), other personality traits might be more important in predicting procrastination, particularly a high degree of impulsiveness $(r=.41)$ and a lack of self-control $(r=-.58)$, which reveal moderate to strong correlations with procrastination; these traits are often referred to as key components in other behavior problems related to self-regulation (Moffitt et al., 2011). In terms of intelligence and aptitude ( $r=.03$ ), as well as positive affect $(r=-.17)$, the correlations are either nonexistent or small, indicating that none of these personality traits should be related to procrastination (Steel, 2007). 


\subsection{Environmental Stimuli}

According to Steel (2007), procrastination tends to increase with the publication year of the research, revealing a possible increase of procrastination in society in general. Self-reported problems of procrastination appeared among $4 \%-5 \%$ of the adult population during the 1970s, compared to the most recent figures of $15 \%-20 \%$ (Steel, 2012). A greater awareness and the popularity of procrastination as a phenomenon might be one explanation behind this growth, but the availability of immediate gratification and modern information technology (e.g., Internet, computers, and smartphones) could also be involved (Andersson, Cuijpers, Carlbring, Riper, \& Hedman, in press). Furthermore, a rise in the demand for self-control may also play an important role, exacerbating the difficulties of self-regulation experienced by some individuals (Moffitt et al., 2011). Both distractibility ( $r$ $=.45)$ and organization $(r=-.36)$ are moderately correlated with procrastination, indicating that a greater susceptibility to environmental stimuli interferes with the individual's ability to stay focused on a task, while greater organizational skills may prevent procrastination from occurring (Steel, 2007).

\subsection{Irrational Beliefs}

Clinical experience concerning the treatment of procrastination assumes that irrational beliefs such as assumptions, core beliefs, and negative automatic thoughts often result in the delay of commitments. In fact, research on procrastination has long regarded procrastination as a behavioral problem primarily related to the irrational or dysfunctional beliefs of the individual (Pychyl \& Flett, 2012), for example perfectionism, unrealistic expectations, and low self-esteem. However, the average correlation between irrational beliefs and procrastination is generally irregular and weak $(r=.17)$, depending on which forms of irrational beliefs are surveyed and whether the study design is experimental or retrospective (Steel, 2007). Socially prescribed perfectionism, one's belief that other people set high standards for oneself, exhibits a small correlation with procrastination $(r=.18)$, presumably owing to the fear of failure (Steel, 2007). Self-prescribed perfectionism, on the other hand, is unrelated to procrastination (Haycock, McCarthy, \& Skay, 1998). In terms of self-esteem $(r=-.27)$ and self-efficacy $(r=$ -.38), the association with procrastination is moderate (Steel, 2007), indicating that high self-esteem and high self-efficacy could prevent activities from being postponed because of irrational beliefs. Furthermore, self-handicapping is also moderately correlated with procrastination $(r=.46)$, revealing a potential tendency for procrastinators to undertake and spend more time on commitments that are likely to fail and to engage in activities unrelated to the task at hand (Steel, 2007; Lay, Knish, \& Zanatta, 1992). In other words, procrastinators defer tasks and assignments to a greater degree than others do because of self-doubt and a lack of self-efficacy, are more prone to give up their efforts when they encounter problems in their performance, and are at risk of becoming occupied by behaviors that are self-defeating (Ferrari, 1991; Ferrari \& Tice, 2000).

\subsection{Task Characteristics}

Experiencing a commitment as aversive is often portrayed as an explanation for its delay, and this is supported by research investigating the relation between task characteristics and procrastination, representing a moderate correlation $(r=.40)$ (Steel, 2007). A task's unpleasantness and an individual's boredom and lack of interest are some of the most common reasons for deferring a task or assignment, and the more anxiety or effort it produces, the more likely the person is to procrastinate (Ferrari \& Scher, 2000; Pychyl, Lee, Thibodeau, \& Blunt, 2000). However, further exploration regarding tasks' characteristics also reveals a relationship with conscientiousness and habitual procrastination, demonstrating a possible moderating effect (Lay \& Brokenshire, 1997); that is, people who procrastinate recurrently might experience many of life's commitments as more aversive. This is supported by evidence implying that a tendency to boredom is moderately correlated with procrastination ( $r$ $=.40)$, while sensation seeking has a small correlation with procrastination $(r=.17)$, suggesting that some individuals may be more responsive to boredom and may defer their commitments in order to become more motivated (van Eerde, 2000).

\subsection{Motivational Factors}

Motivational factors have been investigated in relation to procrastination to a great extent (Steel, 2007), mainly involving different constructs of motivation (e.g., extrinsic and intrinsic motivation). Achievement motivationthe need for achievement in particular-is, for instance, moderately correlated with procrastination $(r=-.35)$ 
(Steel, 2007), indicating a greater tendency to delay a commitment if the individual lacks a motive or the drive to accomplish it. Similarly, intrinsic motivation is also related to procrastination, illustrating a small correlation between high intrinsic motivation and less procrastination $(r=-.26)$ (Steel, 2007). The association with extrinsic motivation is, however, unclear, and Steel (2007) points out that achievement motivation could incorporate extrinsic elements as well-that is, working toward a goal is experienced as rewarding in itself. Intrinsic and extrinsic motivation may therefore be equally important in explaining procrastination, but they may possibly affect individuals differently (Gröpel \& Steel, 2008). Furthermore, research on motivational factors has not revealed a relation between intention and procrastination $(r=-.03)$, meaning that people who procrastinate recurrently do not lack an intention to initiate or complete their tasks or assignments but, rather, experience difficulties acting on their intentions (i.e., the intention-action gap) (Steel, Brothen, \& Wambach, 2001).

\subsection{Motivational Theories}

Theories of motivation are often used to describe decision-making processes among individuals, groups, and organizations, including the choice to postpone tasks and assignments (Steel, 2007). According to Steel and König (2006), the field of motivation consists of numerous attempts to explain procrastination stemming from research in economy, psychology, sociology, and cognitive neuroscience. However, although each theory adds its own perspective, these theoretical viewpoints have not been integrated. Steel and König (2006) therefore proposed a general model of motivation that incorporates a variety of aspects believed to affect decision-making processes: temporal motivational theory (TMT). The model is derived from hyperbolic discounting (Ainslie \& Haslam, 1992), expectancy theory (Vroom, 1964), cumulative prospect theory (Tversky \& Kahneman, 1992), and need theory (Dollard \& Miller, 1950) and has been put forward by Steel (2012) as a motivational approach to understanding procrastination. Hyperbolic discounting concerns the tendency to choose activities that generate a more immediate reward instead of future payoffs (Ainslie \& Haslam, 1992) — that is, being more motivated by instant gratification. Expectancy theory is one of several classic economic theories regarding the propensity to determine the outcome of an activity by considering its value and the probability of achieving that value (Vroom, 1964), by asking which activity will most likely generate the largest reward. Cumulative prospect theory is an essential part of behavioral economics, involving the process of considering losses and gains in reference to a specific baseline or status quo, in which losses are given a greater weight (Tversky \& Kahneman, 1992) — that is, by contrasting potential profits with possible setbacks. Need theory is one of the earlier psychological theories that explain motivation as the drive to perform behaviors that permit satisfaction or the release of the need per se (Dollard \& Miller, 1950); it is similar to Hull's drive-reduction theory (Hull, 1935), the idea that one chooses the activities that appease or satiate a certain need. As a whole, TMT suggests that an individual will engage in a commitment by considering its utility or benefit based on four different variables-the expectation of achieving an anticipated outcome, the value of that outcome, the timing of that outcome, and the sensitivity to delay referred to collectively as the procrastination equation (Steel, 2012). In other words, becoming motivated is related to the value assigned to a given activity, the expectancy that one can accomplish that activity, the immediacy of the reward, and one's ability to delay gratification. However, although all the variables are important in order to initiate or complete a given course of action, individuals are likely to determine the utility or benefit of a commitment differently depending on the influence of each variable (Steel, 2012).

\subsection{Learning Theory}

The relation between a behavior and the outcome of that behavior has long been of interest in learning theory (Biglan, 2003; Yoman, 2008). Classical and operant conditioning and, more recently, relational frame theory, have been used to explain the frequency, intensity, and duration of a particular response and are considered fundamental elements of CBT (Salzinger, 1996; Haynes, Leisen, \& Blaine, 1997). The development and maintenance of different psychiatric conditions is, for instance, influenced by learning theory - that is, by the functional analysis of depression (Ferster, 1973) or by the cognitive case conceptualization of social phobia (Clark \& Wells, 1995). Learning theory is also used to understand procrastination and is included in several motivational theories (Steel \& König, 2006). Steel (2007) discusses some of the major underpinnings of TMT using the matching law (Chung \& Hernstein, 1967), schedules of reinforcement (Ainslie, 1992), and sensitivity to delay (Mazur, 2001). The matching law describes the relationship between the rate of responses and the rate of reinforcers (Hernstein, 1970)—in other words, the correlation between a behavior and its consequences. Schedules of reinforcement 
comprise the effect of timing, ratio, and the interval of rewards and punishments on a response (Ferster \& Skinner, 1957), indicating whether variable or fixed intervals will increase, decrease, or sustain a behavior. Sensitivity to delay involves the ability to defer immediate gratification in order the complete a given course of actionin other words, the capacity to postpone a reward (Mazur, 1996). Both schedules of reinforcement and sensitivity to delay are essential to comprehending procrastination, as the timing of the reward and the person's susceptibility to immediate gratification are assumed to be responsible for the delay of tasks and assignments (van Eerde, 2000). Long-term goals might therefore interfere with one's ability to perform a given course of action, particularly since distractions relies on a variable interval schedule, whereas working on a commitment depends on a fixed interval schedule (Stromer, McCormas, \& Rehfeldt, 2000).

\subsection{Self-Efficacy Theory}

Believing in one's ability to perform a given course of action is important in order to carry out many of the tasks and assignments people face on a day-to-day basis. Self-efficacy has therefore been proposed as a possible explanation for procrastination, indicating that low expectations should be associated with an increased tendency to procrastinate (Judge \& Bono, 2001). According to Bandura (1977), self-efficacy refers to the efficacy expectations related to performing a certain behavior, as well as the outcome expectations concerning the ability to achieve an anticipated outcome. Hence, if either one is low, the motivation to initiate work on or to fulfill a commitment should also be low, resulting in fearful and avoidant behavior and, in turn, procrastination (Grunschel, Patrzek, \& Fries, 2013). Research on the negative automatic thoughts associated with procrastination supports this notion, as self-reported cognitions often involve statements that indicate low self-efficacy: "This is too hard," "I’m never going to make it,” or “I haven’t succeeded before, so why should I even bother?” Self-efficacy theory is also an essential part of efficacy performance spirals (Lindsley, Brass, \& Thomas, 1995)—that is, downward or upward spirals caused by the efforts invested in an activity and the results stemming from that activity. In essence, individuals who are fearful of making mistakes and doubt their ability to do well will probably engage in a commitment with low self-efficacy and usually at the last minute, leading to inadequate performance that has a detrimental effect on the final results. Consequently, the ability to meet similar commitments in the future may be judged negatively, producing even lower self-efficacy and putting the person at risk of producing self-fulfilling prophecies (Bandura, 1977). Lack of self-efficacy and the development of downward spirals could therefore be essential to comprehending the maintenance of procrastination, indicating that many individuals are likely to continue to procrastinate unless their self-efficacy increases.

\subsection{Biases and Heuristics}

Research on decision-making processes has extensively explored the biases and heuristics used by individuals when choosing among competing activities, particularly when assessing different financial outcomes (Kahneman, 2003). Kahneman and Tverksy (1979), for instance, proposed a number of biases and heuristics that aid information processing by finding satisfactory solutions to decisions made under cognitive load that are regarded as a fundamental part of behavioral economics (Tverksy \& Kahneman, 1992). Although rarely used to understand behavioral problems, biases and heuristics could add valuable knowledge regarding the decisionmaking processes that affect the maintenance of psychiatric conditions, similar to the way dysfunctional or maladaptive beliefs are often explored in cognitive therapy (Beck, 1970). In terms of deferring tasks and assignments, several biases and heuristics might explain the decision to procrastinate. Present bias refers to the process of overestimating the current situation when evaluating the outcome of various activities (Frederick, Loewenstein, \& O’Donoghue, 2002), to underestimate the fact that preferences may change over time. Planning fallacy involves the tendency to overlook prior experiences when planning for the future (Koole \& van't Spijker, 2000), discarding information about previous difficulties that could facilitate more realistic goal setting. Projection bias concerns the procedure of using the present in order to predict a future behavior (Loewenstein, O'Donoghue, \& Rabin, 2003)— that is, setting goals based on current ambitions and underrating the potential of wanting to change those ambitions. Future discounting consists of the inclination to discredit the value of future events (Laibson, 1997), giving greater weight to immediate rewards. In particular, planning fallacy and future discounting are assumed to be related to procrastination, for they result in poor time management and the inability to learn from past difficulties faced in tasks and assignments, as well as the propensity to choose those activities that result in immediate gratification instead of future rewards (Steel \& König, 2006). 


\subsection{Negative Consequences}

Procrastination involves the postponement of a given course of action and is thus presumed to affect the performance of tasks and assignments, particularly those related to school and work (Tice \& Baumeister, 1997). However, although procrastination is highly stressful, the average correlation between procrastination and performance is generally quite small and inconsistent $(r=-.19)$, revealing only weak associations with course grades $(r=-.25)$, assignments $(r=-.21)$, and the outcome on final exams $(r=-.17)$ (Steel, 2007). Self-reported difficulties involving academic procrastination reveal high correlations between the general tendency to procrastinate and cognitive functioning $(r=-.42)$, the quantity of postponed commitments $(r=.72)$, and the problems stemming from procrastination $(r=.59)$ (Steel, 2007), but procrastination might not necessarily be related to lower performance. Steel (2007) therefore suggests that deferring a commitment does not always have to be harmful, even though it seems to have a slight negative impact and is almost never a particularly helpful behavior. In terms of financial well-being, the relation with procrastination is moderate ( $r=-.42)$ (Steel, 2007), indicating a detrimental effect on economy when one delays decisions or activities related to personal finances. Likewise, there is a small correlation between procrastination and career and financial success $(r=-.26)$ (Steel, 2007), indicating that postponing tasks and assignments has a negative effect on one's ability to perform and progress within a profession, a trend that in turn should result in fewer raises and career opportunities. In regard to mental health, the relation between procrastination and well-being reveals a moderate correlation $(r=-.28)$, implying that delaying commitments is associated with poorer mental health in general, and a small correlation with stress in particular $(r=.20)$ (Stead et al., 2010). Research also reveals a moderate correlation with worry $(r$ $=.31$ ) (van Erde, 2003), and feelings of guilt $(r=.42)$ (Pychyl et al., 2000), but no consistent relationship with mood (Steel, 2007). Closer examination of procrastination reveals that deferring tasks and assignments probably results in less stress early on but increases closer to the deadline, generating more stress in the long run (Tice \& Baumeister, 1997). In addition, procrastination is also weakly to moderately correlated with physical health, contributing to treatment delay $(r=.19)$ and is associated with fewer wellness behaviors $(r=-.24)$, particularly medical checkups $(r=-.22)$ and dental checkups $(r=-.30)$, leading to greater illness $(r=-.20)$ and acute health problems $(r=.17)$ (Sirios, Melia-Gordon, \& Pychyl, 2003; Sirios, 2007). In sum, postponing tasks and assignments contributes to a wide range of negative consequences that affect both mental and physical health, as well as the person's ability to achieve goals and ambitions. Treatment interventions that specifically target procrastination are therefore important in order to enhance well-being and facilitate greater independence among those individuals who recurrently delay fulfilling their commitments.

\section{Treating Procrastination}

\subsection{Idiographic Approach}

Research provides little support for considering procrastination a homogeneous trait, instead suggesting that chronically deferring commitments should be regarded as a behavioral effect (Day et al., 2000). This notion is supported by Steel (2010), who has found inconclusive evidence for the division of procrastination into different subtypes (i.e., arousal, avoidant, and decisional procrastination). Consequently, procrastination might be better explained as a behavioral problem that can differ in character or topography but shares the same underlying mechanisms-namely, the preference for an immediate reward or escape from a potentially aversive experience-highlighting responses that are of functional equivalence (Horner \& Day, 1991). An idiographic approach could therefore be useful in order to explore what maintains the tendency to procrastinate, such as a cognitive case conceptualization or a functional analysis, which in turn would affect the treatment interventions deemed suitable for a particular individual (Hofmann, Asmundson, \& Beck, 2013; Haynes et al., 1997). This corresponds with TMT, which postulates that tasks and assignments are postponed for different reasons, based on how the utility or benefit of those commitments are being determined (e.g., lack of value, low expectancy, time preceding a reward, sensitivity to delay) (Steel \& König, 2006). In other words, even though all variables are responsible for procrastination to some extent, their influence may vary owing to internal and external factors: some individuals procrastinate because insufficient value or nonexistent rewards are associated with the task, while others engage in procrastination related to their susceptibility to immediate gratification (Steel, 2007; van Eerde, 2000). In addition, an idiographic approach can also provide the individual with valuable information regarding its present difficulties (Haynes, Kaholokula, \& Nelson, 1999), raising awareness of the behavioral 
problem, increasing self-efficacy and independence, facilitating the implementation of treatment interventions, and minimizing the risk of relapse (Yoman, 2008). Despite its widespread use in CBT for a number of psychiatric conditions (Virués-Ortega \& Haynes, 2005), an idiographic approach to procrastination using a cognitive case conceptualization or a functional analysis are seldom mentioned in the research. However, van Essen, van den Heuvel and Ossebaard (2004), and van Horebeek, Michielsen, Neyskens and Depreeuw (2004) provide some examples in which the functional analysis of procrastination was incorporated in group-therapy settings, engaging individuals in their own treatment and, in turn, changing the perspective on their behavioral problem from viewing it as unchangeable to regarding it as manageable.

\subsection{Behavioral Interventions}

Treatment interventions intended to reduce procrastination often consist of several behavioral measures that increase automaticity, facilitate time management, and prevent the individual from becoming distracted while working on tasks and assignments (van Eerde, 2000). First, since procrastination is defined as an active choice between competing activities, limiting the number of decisions involved in performing commitments is essential (Silver, 1974). Stimulus control can, for instance, be used to remove aspects that might interfere with the initiation or completion of a given course of action (Mulry, Fleming, \& Gottschalk, 1994), such as disabling notifications on the computer or smartphone and using designated work areas free from distractions and other forms of immediate gratification. Likewise, stimulus cues can prescribe when and where to engage in actions related to work (Ziesat, Rosenthal, \& White, 1978)—for instance, scheduling tasks and assignments to be done in specific locations, such as the library or the office. This might also facilitate automaticity, as it becomes less ambiguous in which context the individual is supposed to perform his or her commitments (Neal, Wood, Labrecque, \& Lally, 2012). In general, all treatment interventions that promote routine are fundamental in inhibiting procrastination (Steel, 2007), similar to using timetables and predetermined activities in a behavioral activation treatment for depression (Jacobson, Martell, \& Dimidjian, 2001). Establishing routines is also important in order to create a normal diurnal rhythm and to prevent mental fatigue, thus enhancing performance and aligning the individual with social zeitgebers - for instance, working on commitments during daytime and using the evening to recover or to engage in social activities (Ehlers, Frank, \& Kupfer, 1988). A similar concept is derived from ego depletion (Baumeister, Bratlavsky, Muraven, \& Tice, 1998), referred to as the decrease in self-control caused by a lack of energy. Preventing ego depletion is important in averting procrastination, as procrastinators often tend to postpone their commitments until the last minute or to work long periods without pausing, resulting in insufficient energy to perform well, which in turn produces more procrastination (Digdon \& Howell, 2006).

Second, because procrastination is associated with avoidance behavior, gradually exposing the individual to the avoided activity should be beneficial in reducing the feelings that lead to deferring tasks and assignments (Brown, 1991). Boredom, worry, and unpleasantness are several experiences reported by procrastinators (Schraw, Wadkins, \& Olafson, 2007), indicating that some form of exposure is probably required to break through the initial threshold that inhibits the individual from engaging in his or her commitments. Prescribing the minimal amount of effort the individual is willing to exert could be implemented as a means of overcoming the feelings that cause procrastination (Burka \& Yuen, 2008)—for instance, working for fifteen minutes before evaluating whether to continue. This minimal level can be determined by either input, the effort that needs to be put into the activity, or output, the result that needs to be achieved (Steel, 2012). In addition, goal setting is generally acknowledged as an essential treatment intervention for procrastination because insufficient or inadequate goals often impair problem solving and lower motivation (Locke \& Latham, 2002). Norcross (2012) formulates this as "vague goals beget vague efforts", highlighting the importance of setting goals that are specific enough to be instructive and measurable in order to promote the performance of goal-directed behaviors. Concrete goals can also enhance productivity, as they provide feedback that can correct performance and reinforce the intended behavior (Lindsley et al., 1995). Furthermore, goal setting should always be accompanied by dividing long-term goals into subgoals since this helps the individual with issues related to time management (Steel \& König, 2006), particularly in terms of goals that involve considerable effort.

Third, procrastination is often related to a lack of value, leading the individual to postpone fulfilling a commitment in favor of activities that generate more immediate gratification (Steel, 2007). This can partly be circumvented by using adequate goal setting that increases motivation (Boice, 1989). However, for many procrastinators, most tasks and assignments that need completion will probably be experienced as unrewarding, war- 
ranting treatment interventions that specifically target the value of performing the correct actions (Bandura \& Schunk, 1981). Basically, this involves increasing extrinsic or intrinsic motivation, depending on individual preferences and the type of commitment being postponed (Steel, 2007). Extrinsic motivation benefits from using rewards that are contingent on the implementation of a certain behavior (Eisenberg, Cortis Park, \& Frank, 1976), such as having a cup of coffee after completing one hour of writing. Eisenberg (1992) refers to this as learned industriousness, using continuous reinforcers when working on tasks and assignments instead of rewarding only the outcome, a concept similar to Premack's principle (Premack, 1959), the idea that high-frequency behaviors reinforce low-frequency behaviors. Some individuals might also profit from fusing (Murray, 1938), combining the commitment being postponed with an activity that is experienced as more rewarding —-for instance, studying with classmates rather than alone. In terms of intrinsic motivation, rewards might not be enough to motivate an individual (Rawsthorne \& Elliot, 1999), especially if the postponed activity does not address aspects that are experienced as personally meaningful. Hence, treatment interventions that increase one's awareness of values might be essential to increasing commitment (Hayes, Luoma, Bond, Masuda, \& Lillis, 2006), that is, to clarify the meaning of performing a specific task. This could be particularly important regarding existential questions associated with procrastination, most notably among students (e.g., the relationship between striving toward a university degree and the individual's own values).

\subsection{Cognitive Interventions}

Treatment interventions involving cognitive measures are often used to target the influence of irrational beliefs on procrastination (Pychyl \& Flett, 2012). Perfectionism, fear of failure, and self-doubt are all examples of cognitions that might interfere with the ability to engage in tasks and assignments (Schraw et al., 2007). Although the general relationship between irrational beliefs and procrastination is irregular and weak (Steel, 2007), clinical experience suggests that attending to assumptions, core beliefs, and negative automatic thoughts may be essential in order to prevent the individual from postponing commitments (Flett, Stainton, Hewitt, Sherry, \& Lay, 2012). First, since irrational beliefs could be associated with self-handicapping and avoidance behaviors, cognitive restructuring may be used to make the individual mindful of the cognitions that interfere with implementing the correct responses (McDermott, 2004): for instance, "It is absolutely essential for the outcome to be perfect," and "If I'm not motivated, I might as well do something else." Cognitive restructuring can also facilitate the performance of new and more adaptive behaviors, particularly when accompanied by behavioral experiments (Bennett-Levy, 2003); such as handing in an essay despite fear of failure and exploring the thoughts and emotions that are observed. This is particularly important in terms of raising self-esteem and self-efficacy, both associated with procrastination (van Eerde, 2000). Efficacy performance spirals can, for instance, be used to curb the maintenance of self-fulfilling prophecies by gradually exposing the individual to activities that are being avoided (Lindsley et al., 1995), such as completing tasks and assignments with increasing difficulty, resulting in corrective feedback and opportunities to reinforce the intended behavior. However, procrastination can also be caused by exaggerated optimism (Vancouver \& Day, 2005), warranting cognitive restructuring and behavioral experiments that target cognitions resulting in ineffective time management and difficulties related to self-control (Vancouver, More, \& Yoder, 2008) (e.g., commencing tasks and assignments earlier than usual, creating action plans for worst-case scenarios).

Second, becoming aware of irrational beliefs might help the individual realize the discrepancy between the current situation and the goals and values that are desirable, in turn affecting motivation and instigating behavior change (Hayes, Levin, Plumb-Villardaga, Villatte, \& Pistorello, 2010). Cognitive restructuring could elucidate the problem of certain cognitions in performing the actions necessary to meet commitments and may increase the individual's willingness to engage in more adaptive responses (McDermott, 2004), for instance, to consider the difficulty of initiating or completing a given course of action if the circumstances always have to be perfect. In addition, motivational interviewing might also be valuable in order to investigate the costs and benefits of procrastination, as well as increasing motivation by letting the individual explore his or her own readiness to change (Miller \& Rollnick, 2012). Open-ended questions, providing summaries and reflections, and steering away from directive measures could, for instance, be used to assess the opportunity to administer other treatment interventions, avoid confrontation, and increase the individual's commitment in therapy (Treasure, 2004). Furthermore, cognitive interventions that specifically target irrational beliefs related to time management and goal setting have been proposed to promote more realistic performance judgments and the individual's engagement 
in goal-directed behaviors (van Eerde, 2000); particularly useful are for example implementation intentions and mental contrasting (Gollwitzer \& Brandstätter, 1997; Oettingen \& Mayer, 2002). Implementation intentions involve the use of verbal if ... then statements that facilitate later memory retrieval and limit the number of decisions that can be made (e.g., "When I arrive at the office, I will start working on my presentation."), which in turn might help individuals inhibit their tendency to procrastinate (Gollwitzer, Sheeran, Michalski, \& Seifert, 2009). Mental contrasting involves a visual technique similar to imaginal exposure that is intended to increase motivation and highlight the gap between the current situation and future goals, highlighting which steps are necessary in order to achieve a specific outcome, overcoming the risk of becoming engulfed and passive in the thinking process alone (Oettingen, Mayer, Thorpe, Janetzke, \& Lorenz, 2005).

\subsection{Clinical Trials}

Research on procrastination has paid little attention to which treatment interventions might benefit individuals who engage in procrastinatory behavior (Steel, 2007). Hence, little is known about the efficacy of therapy for procrastination, even though it has been proposed that CBT might be suitable for addressing behavioral problems associated with self-regulatory failure (Pychyl \& Flett, 2012; Uzun Ozer, Demir, \& Ferrari, 2013). Furthermore, research regarding treatment interventions that target procrastination has primarily consisted of single-case trials (Karas \& Spada, 2009), particularly involving the postponement of study-related activities (i.e., procrastination among a student population). Though it is informative from a clinical perspective, such idiographic research does not examine efficacy on a group level, leaving both therapists and researchers without knowledge of whether therapy is appropriate for procrastination, who might benefit from therapy, and which treatment interventions mediate treatment outcome. However, a number of attempts to evaluate group therapy for procrastination have been made, yielding promising results in terms of targeting the problems associated with deferring tasks and assignments (Pychyl \& Flett, 2012). Van Essen et al. (2004) and van Horebeek et al. (2004) used both behavioral and cognitive interventions intended to alleviate problems of procrastination among students and reported positive results for procrastination, test anxiety, and course grades. Tuckman and Schouwenburg (2004) took a similar approach involving task management, goal setting, and behavioral interventions, with positive results in terms of course grades over two academic semesters. The major disadvantages of these trials - and of research exploring treatment interventions for procrastination in general—are the use of quasiexperimental methods and the lack of randomization, which limits the generalizability of the results. In fact, there currently exists only one randomized controlled trial investigating treatment interventions for procrastination (Rozental \& Carlbring, 2013), making it difficult to determine the efficacy of CBT for procrastination. Another drawback of the research is the use of self-report measures intended to determine the severity of procrastination that have not been validated on a clinical population. Several outcome measures have been proposed and are often implemented when investigating the prevalence of procrastination among students and the adult population, most notably the General Procrastination Scale (Lay, 1986), the Adult Inventory of Procrastination (Steel, 2010), the Decisional Procrastination Questionnaire (Steel, 2010), the Procrastination Assessment ScaleStudents (Solomon \& Rothblum, 1984), and the Procrastination Scale (Tuckman, 1991). However, although examined in terms of their internal consistency, none of these self-report measures have been evaluated with regard to their test-retest reliability. In addition, the lack of established cutoffs makes it difficult to differentiate clinical for non-clinical populations of procrastinators. Hence, Steel (2010) reviewed the psychometric properties of all of the available self-report measures of procrastination using factor analysis, suggesting a new outcome measure with improved correlations to key constructs presumed to be related to procrastination — namely, the Pure Procrastination Scale. Still, the clinical utility of these different self-report measures is unknown, warranting further research on whether they can be useful on a clinical population, as well as the relationships to other psychiatric conditions and overall well-being (e.g., depression, anxiety, and quality of life).

\section{Conclusion}

The current paper has explored prior research on procrastination in order to provide a theoretical and clinical understanding of its occurrence and characteristics. In essence, different perspectives from motivational theory, learning theory, self-efficacy theory, and biases and heuristics could help therapists and researchers comprehend procrastination, choose among treatment interventions, and investigate what mediates treatment outcome (Steel, 2007). TMT is proposed by Steel and König (2006) as an integrated account of motivation that may facilitate an 
understanding of procrastination, particularly for those individuals who struggle to apprehend and cope with their behavioral problems. Treatment interventions stemming from both a behavioral and a cognitive perspective are assumed to be beneficial in terms of managing procrastination, improving motivation, and increasing selfefficacy. However, an idiographic approach based on a cognitive case conceptualization or functional analysis is deemed appropriate because procrastination can be caused by different variables (e.g., expectancy, value, time, and sensitivity to delay) (Steel, 2007; van Eerde, 2003).

The current paper has also reviewed previous research regarding treatment interventions for procrastination, revealing both promising results and limitations. Single-case trials and evaluations of group therapy are informative and useful, particularly in guiding therapists in their clinical work. Meanwhile, less effort has been made to implement randomized controlled trials when investigating the usefulness of therapy for procrastination. Hence, there is currently insufficient evidence to support the notion that CBT is suitable for the treatment of procrastination. Further research is therefore necessary, employing randomized conditions in order to evaluate its efficacy. In addition, the use of self-report measures has not yet been satisfactory in terms of differentiating clinical from non-clinical populations of procrastinators, as well as investigating the relationship with other psychiatric conditions and overall well-being. Psychometrically sound outcome measures are thus warranted, along with cutoffs distinguishing procrastination from other behavioral problems and comorbid conditions.

\section{References}

Ainslie, G. (1992). Picoeconomics: The Strategic Interaction of Successive Motivational States within the Person. New York, NY: Cambridge University Press.

Ainslie, G., \& Haslam, N. (1992). Hyperbolic Discounting. In G. Loewenstein \& J. Elster (Eds.), Choice over Time (pp. 57-92). New York: Russell Sage Foundation.

Andersson, G., Cuijpers, P., Carlbring, P., Riper, H., \& Hedman, E. Internet-Based vs. Face-to-Face Cognitive Behaviour Therapy for Psychiatric and Somatic Disorders: A Systematic Review and Meta-Analysis. World Psychiatry. (in press)

Bandura, A. (1977). Self-Efficacy: Toward a Unifying Theory of Behavioral Change. Psychological Review, 84, $191-215$. http://dx.doi.org/10.1037/0033-295X.84.2.191

Bandura, A., \& Schunk, D. H. (1981). Cultivating Competence, Self-Efficacy, and Intrinsic Interest through Proximal SelfMotivation. Journal of Personality and Social Psychology, 41, 586-598.

http://dx.doi.org/10.1037/0022-3514.41.3.586

Banich, M. T. (2009). Executive Function: The Search for an Integrated Account. Current Directions in Psychological Science, 18, 89-94. http://dx.doi.org/10.1111/j.1467-8721.2009.01615.x

Baumeister, R. F., Bratlavsky, E., Muraven, M., \& Tice, D. M. (1998). Ego Depletion: Is the Active Self a Limited Resource? Journal of Personality and Social Psychology, 74, 1252-1265. http://dx.doi.org/10.1037/0022-3514.74.5.1252

Beck, A. (1970). Cognitive Therapy: Nature and Relation to Behavior Therapy. Behavior Therapy, 1, 184-200. http://dx.doi.org/10.1016/S0005-7894(70)80030-2

Bennett-Levy, J. (2003). Mechanisms of Change in Cognitive Therapy: The Case of Automatic thought Records and Behavioural Experiments. Behavioural and Cognitive Psychotherapy, 31, 261-277. http://dx.doi.org/10.1017/S1352465803003035

Beswick, G., \& Mann, L. (1994). State Orientation and Procrastination. In J. Kuhl \& J. Beckmann (Eds.), Volition and Personality: Action versus State Orientation (pp. 391-396). Gottingen: Hogrefe \& Huber.

Biglan, A. (2003). Selection by Consequences: One Unifying Principle for a Transdisciplinary Science of Prevention. Prevention Science, 4, 213-232. http://dx.doi.org/10.1023/A:1026064014562

Boice, R. (1989). Procrastination, Busyness and Bingeing. Behaviour Research and Therapy, 27, 605-611. http://dx.doi.org/10.1016/0005-7967(89)90144-7

Brown, R. T. (1991). Helping Students Confront and Deal with Stress and Procrastination. Journal of College Student Psychotherapy, 6, 87-102. http://dx.doi.org/10.1300/J035v06n02_09

Burka, J. B., \& Yuen, L. M. (2008). Procrastination: Why You Do It, What to Do about It Now. Cambridge, MA: Da Capo Press.

Carstensen, L. L., Isaacowitz, D. M., \& Charles, S. T. (1999). Taking Time Seriously. American Psychologist, 54, 165-181. http://dx.doi.org/10.1037/0003-066X.54.3.165

Chung, S., \& Herrnstein, R. J. (1967). Choice and Delay of Reinforcement. Journal of the Experimental Analysis of Behavior, 10, 67-74. http://dx.doi.org/10.1901/jeab.1967.10-67 
Clark, D. M., \& Wells, A. (1995). A Cognitive Model of Social Phobia. In R. Heimberg, M. Liebowitz, D. A. Hope, \& F. R. Schneier (Eds.), Social Phobia: Diagnosis, Assessment, and Treatment (pp. 69-93). New York: Guilford Press.

Day, V., Mensink, D., \& O’Sullivan, M. (2000). Patterns of Academic Procrastination. Journal of College Reading and Learning, 30, 120-134. http://dx.doi.org/10.1080/10790195.2000.10850090

Digdon, N. L., \& Howell, A. J. (2006). College Student Who Have an Eveningness Preference Report Lower Self-Control and Greater Procrastination. Chronobiology International, 25, 1029-1046. http://dx.doi.org/10.1080/07420520802553671

Dollard, J., \& Miller, N. E. (1950). Personality and Psychotherapy: An Analysis in Terms of Learning, Thinking, and Culture. New York: McGraw-Hill.

Dryden, W. (2000). Overcoming Procrastination. London: Sheldon Press.

Ehlers, C. L., Frank, E., \& Kupfer, D. J. (1988). Social Zeitgebers and Biological Rhythms: A Unified Approach to Understand the Etiology of Depression. JAMA Psychiatry, 45, 948-952.

http://dx.doi.org/10.1001/archpsyc.1988.01800340076012

Eisenberg, R. (1992). Learned Industriousness. Psychological Review, 99, 248-267. http://dx.doi.org/10.1037/0033-295X.99.2.248

Eisenberg, R., Cortis Park, D., \& Frank, M. (1976). Learned Industriousness and Social Reinforcement. Journal of Personality and Social Psychology, 33, 227-232. http://dx.doi.org/10.1037/0022-3514.33.2.227

Else-Quest, N. M., Hyde, J. S., Goldsmith, H. H., \& Van Hulle, C. A. (2006). Gender Differences in Temperament: A Meta-Analysis. Psychological Bulletin, 132, 33-72. http://dx.doi.org/10.1037/0033-2909.132.1.33

Ferrari, J. R. (1991). Self-Handicapping by Procrastinators: Protecting Self-Esteem, Social-Esteem, or Both? Journal of Research in Personality, 25, 245-261. http://dx.doi.org/10.1016/0092-6566(91)90018-L

Ferrari, J. R., \& Scher, S. J. (2000). Toward an Understanding of Academic and Nonacademic Tasks Procrastinated by Students: The Use of Daily Logs. Psychology in the Schools, 37, 359-366. http://dx.doi.org/10.1002/1520-6807(200007)37:4<367::AID-PITS7>3.0.CO;2-Y

Ferrari, J. R., \& Tice, D. M. (2000). Procrastination as a Self-Handicap for Men and Women: A Task-Avoidance Strategy in a Laboratory Setting. Journal of Research in Personality, 34, 73-83. http://dx.doi.org/10.1006/jrpe.1999.2261

Ferster, C. B. (1973). A Functional Analysis of Depression. American Psychologist, 28, 857-870. http://dx.doi.org/10.1037/h0035605

Ferster, C. B., \& Skinner, B. F. (1957). Schedules of Reinforcement. New York, NY: Appleton-Century-Crofts. http://dx.doi.org/10.1037/10627-000

Flett, G. L., Stainton, M., Hewitt, P. L., Sherry, S. B., \& Lay, C. (2012). Procrastination and Automatic Thoughts as a Personality Construct: An Analysis of the Procrastinatory Cognitions Inventory. Journal of Rational-Emotive \& CognitiveBehavior Therapy, 30, 223-236. http://dx.doi.org/10.1007/s10942-012-0150-z

Frederick, S., Loewenstein, G., \& O’Donoghue, T. (2002). Time Discounting and Time Preference: A Critical Review. Journal of Economic Literature, 40, 351-401. http://dx.doi.org/10.1257/jel.40.2.351

Gollwitzer, P. M., \& Brandstätter, V. (1997). Implementation Intentions and Effective Goal Pursuit. Journal of Personality and Social Psychology, 73, 186-199. http://dx.doi.org/10.1037/0022-3514.73.1.186

Gollwitzer, P. M., Sheeran, P., Michalski, V., \& Seifert, A. E. (2009). When Intentions Go Public: Does Social Reality Widen the Intention-Behavior Gap? Psychological Science, 20, 612-618. http://dx.doi.org/10.1111/j.1467-9280.2009.02336.x

Gröpel, P., \& Steel, P. (2008). A Mega-Trial Investigation of Goal Setting, Interest Enhancement, and Energy on Procrastination. Personality and Individual Differences, 45, 406-411. http://dx.doi.org/10.1016/j.paid.2008.05.015

Grunschel, C., Patrzek, J., \& Fries, S. (2013). Exploring the Reasons and Consequences of Academic Procrastination: An Interview Study. European Journal of Psychology of Education, 28, 841-861. http://dx.doi.org/10.1007/s10212-012-0143-4

Harriott, J. S., \& Ferrari, J. R. (1996). Prevalence of Procrastination among Samples of Adults. Psychological Reports, 78, 611-616. http://dx.doi.org/10.2466/pr0.1996.78.2.611

Haycock, L. A., McCarthy, P., \& Skay, C. L. (1998). Procrastination in College Students: The Role of Self-Efficacy and Anxiety. Journal of Counseling and Development, 76, 317-324. http://dx.doi.org/10.1002/j.1556-6676.1998.tb02548.x

Hayes, S. C., Luoma, J. B., Bond, F. W., Masuda, A., \& Lillis, J. (2006). Acceptance and Commitment Therapy: Model, Processes and Outcomes. Behaviour Research and Therapy, 44, 1-25. http://dx.doi.org/10.1016/j.brat.2005.06.006

Hayes, S., Levin, M. E., Plumb-Villardaga, J., Villatte, J. L., \& Pistorello, J. (2010). Acceptance and Commitment Therapy and Contextual Behavioral Science: Examining the Progress of a Distinctive Model of Behavioral and Cognitive Therapy. 
Behavior Therapy, 44, 180-198. http://dx.doi.org/10.1016/j.beth.2009.08.002

Haynes, S. N., Kaholokula, J. K., \& Nelson, K. (1999). The Idiographic Application of Nomothetic Empirically Based Treatments. Clinical Psychology: Science and Practice, 6, 456-461. http://dx.doi.org/10.1093/clipsy/6.4.456

Haynes, S. N., Leisen, M. B., \& Blaine, D. D. (1997). Design of Individualized Behavioral Treatment Programs Using Functional Analytic Clinical Case Models. Psychological Assessment, 9, 334-348. http://dx.doi.org/10.1037/1040-3590.9.4.334

Hernstein, R. J. (1970). On the Law of Effect. Journal of the Experimental Analysis of Behavior, 13, 243-266. http://dx.doi.org/10.1901/jeab.1970.13-243

Hettema, J. M., Neale, M. C., Myers, J. M., Prescott, C. A., \& Kendler, K. S. (2006). A Population-Based Twin Study of the Relationship between Neuroticism and Internalizing Disorders. American Journal of Psychiatry, 163, 857-864.

http://dx.doi.org/10.1176/appi.ajp.163.5.857

Hofmann, S. G., Asmundson, G. J. G., \& Beck, A. T. (2013). The Science of Cognitive Therapy. Behavior Therapy, 44, 199-212. http://dx.doi.org/10.1016/j.beth.2009.01.007

Horner, R. H., \& Day, H. M. (1991). The Effects of Response Efficiency on Functionally Equivalent Competing Behaviors. Journal of Applied Behavior Analysis, 24, 719-732. http://dx.doi.org/10.1901/jaba.1991.24-719

Hull, C. L. (1935). The Conflicting Psychologies of Learning: A Way Out. Psychological Review, 42, 491-516. http://dx.doi.org/10.1037/h0058665

Jacobson, N. S., Martell, C. R., \& Dimidjian, S. (2001). Behavioral Activation Treatment for Depression: Returning to Contextual Roots. Clinical Psychology: Science and Practice, 8, 255-270. http://dx.doi.org/10.1093/clipsy.8.3.255

Judge, T. A., \& Bono, J. E. (2001). Relationship of Core Self-Evaluations Traits-Self-Esteem, Generalized Self-Efficacy, locus of Control, and Emotional Stability-With Job Satisfaction and Job Performance: A Meta-Analysis. Journal of Applied Psychology, 86, 80-92. http://dx.doi.org/10.1037/0021-9010.86.1.80

Kahneman, D. (2003). Maps of Bounded Rationality: Psychology for Behavioral Economics. American Economic Review, 93, 1449-1475. http://dx.doi.org/10.1257/000282803322655392

Kahneman, D., \& Tversky, A. (1979). Intuitive Prediction: Biases and Corrective Procedures. TIMS Studies in Management Science, 12, 313-327.

Karas, D., \& Spada, M. M. (2009). Brief Cognitive-Behavioural Coaching for Procrastination: A Case Series. Coaching: An International Journal of Theory, Research and Practice, 2, 44-53.

Klingsieck, K. B. (2013). Procrastination: When Good Things Don’t Come to Those Who Wait. European Psychologist, 18, 24-34. http://dx.doi.org/10.1027/1016-9040/a000138

Koole, S., \& van’t Spijker, M. (2000). Overcoming the Planning Fallacy through Willpower: Effects of Implementation Intentions on Actual and Predicted Task-Completion Times. European Journal of Social Psychology, 30, 873-888. http://dx.doi.org/10.1002/1099-0992(200011/12)30:6<873::AID-EJSP22>3.0.CO;2-U

Laibson, D. (1997). Golden Eggs and Hyperbolic Discounting. Quarterly Journal of Economics, 112, 443-478. http://dx.doi.org/10.1162/003355397555253

Lay, C. H. (1986). At Last, My Research Article on Procrastination. Journal of Research in Personality, 20, 474-495. http://dx.doi.org/10.1016/0092-6566(86)90127-3

Lay, C. H., \& Brokenshire, R. (1997). Conscientiousness, Procrastination, and Person-Task Characteristics in Job Searching by Unemployed Adults. Current Psychology: Developmental, Learning, Personality, Social, 16, 83-96. http://dx.doi.org/10.1007/s12144-997-1017-9

Lay, C. H., Knish, S., \& Zanatta, R. (1992). Self-Handicappers and Procrastinators: A Comparison of Their Practice Behavior Prior to an Evaluation. Journal of Research in Personality, 26, 242-257. http://dx.doi.org/10.1016/0092-6566(92)90042-3

Lindsley, D. H., Brass, D. J., \& Thomas, J. B. (1995). Efficacy-Performance Spirals: A Multilevel Perspective. The Academy of Management Review, 20, 645-678.

Locke, E., \& Latham, G. (2002). Building a Practically Useful Theory of Goal Setting and Motivation. American Psychologist, 57, 705-717. http://dx.doi.org/10.1037/0003-066X.57.9.705

Loewenstein, G., O’Donoghue, T., \& Rabin, M. (2003). Projection Bias in Predicting Future Utility. The Quarterly Journal of Economics, 118, 1209-1248. http://dx.doi.org/10.1162/003355303322552784

Mazur, J. E. (1996). Procrastination by Pigeons: Preferences for Larger, More Delayed Work Requirements. Journal of the Experimental Analysis of Behavior, 65, 159-171. http://dx.doi.org/10.1901/jeab.1996.65-159

Mazur, J. E. (2001). Hyperbolic Value Addition and General Models of Animal Choice. Psychological Review, 108, 96-112. http://dx.doi.org/10.1037/0033-295X.108.1.96

McDermott, S. P. (2004). Treating Anxiety Disorders Using Cognitive Therapy Techniques. Psychiatric Annals, 34, 859- 
872.

Miller, W. R., \& Rollnick, S. (2012). Motivational Interviewing (3rd ed.). New York: Guilford Press.

Moffitt, T. E., Arseneault, L., Belsky, D., Dickson, N., Hancox, R. J., Harrington, H. L., Houts, R., Poulton, R., Roberts, B. W., Ross, S., Sears, M. R., Thomson, W. M., \& Caspi, A. (2011). A Gradient of Childhood Self-Control Predicts Health, Wealth, and Public Safety. Proceedings of the National Academy of Sciences of the United States of America, 108, 26932698. http://dx.doi.org/10.1073/pnas.1010076108

Mulry, G., Fleming, R., \& Gottschalk, A. C. (1994). Psychological Reactance and Brief Treatment of Academic Procrastination. Journal of College Student Psychotherapy, 9, 41-56. http://dx.doi.org/10.1300/J035v09n01 04

Murray, H. A. (1938). Explorations in Personality. New York: Oxford University Press.

Neal, D. T., Wood, W., Labrecque, J., \& Lally, P. (2012). How Do Habits Guide Behavior? Perceived and Actual Triggers of Habits in Daily Life. Journal of Experimental Social Psychology, 48, 492-498.

http://dx.doi.org/10.1016/j.jesp.2011.10.011

Norcross, J. (2012). Changeology. New York: Simon \& Schuster.

O’Donoghue, T., \& Rabin, M. (1999). Incentives for Procrastinators. Quarterly Journal of Economics, 114, 769-816. http://dx.doi.org/10.1162/003355399556142

Oettingen, G., \& Mayer, D. (2002). The Motivating Function of Thinking about the Future: Expectations versus Fantasies. Journal of Personality and Social Psychology, 83, 1198-1212. http://dx.doi.org/10.1037/0022-3514.83.5.1198

Oettingen, G., Mayer, D., Thorpe, J. S., Janetzke, H., \& Lorenz, S. (2005). Turning Fantasies about Positive and Negative Futures into Self-Improvement Goals. Motivation and Emotions, 29, 236-266.

http://dx.doi.org/10.1007/s11031-006-9016-y

Ozer, D. J., \& Benet-Martínez, V. (2006). Personality and the Prediction of Consequential Outcomes. Annual Review of Psychology, 57, 401-421. http://dx.doi.org/10.1146/annurev.psych.57.102904.190127

Premack, D. (1959). Toward Empirical Behavior Laws: I. Positive Reinforcement. Psychological Review, 66, $219-233$. http://dx.doi.org/10.1037/h0040891

Pychyl, T. A., \& Flett, G. L. (2012). Procrastination and Self-Regulatory Failure: An Introduction to the Special Issue. Journal of Rational-Emotive \& Cognitive-Behavior Therapy, 30, 203-212. http://dx.doi.org/10.1007/s10942-012-0149-5

Pychyl, T. A., Lee, J. M., Thibodeau, R., \& Blunt, A. (2000). Five Days of Emotion: An Experience Sampling Study of Undergraduate Student Procrastination. Journal of Social Behavior and Personality, 15, 239-254.

Rawsthorne, L., \& Elliot, A. (1999). Achievement Goals and Intrinsic Motivation: A Meta-Analytic Review. Personality and Social Psychology Review, 3, 326-344. http://dx.doi.org/10.1207/s15327957pspr0304_3

Rozental, A., \& Carlbring, P. (2013). Internet-Based Cognitive Behavior Therapy for Procrastination: Study Protocol for a Randomized Controlled Trial. JMIR Research Protocols, 2, e46. http://dx.doi.org/10.2196/resprot.2801

Sabini, J., \& Silver, M. (1982). Moralities of Everyday Life. New York: Oxford University Press.

Salzinger, K. (1996). Reinforcement History: A Concept Underutilized in Behavior Analysis. Journal of Behavior Therapy and Experimental Psychiatry, 27, 199-207. http://dx.doi.org/10.1016/S0005-7916(96)00037-7

Schraw, G., Wadkins, T., \& Olafson, L. (2007). Doing the Things We Do: A Grounded Theory of Academic Procrastination. Journal of Educational Psychology, 99, 12-25. http://dx.doi.org/10.1037/0022-0663.99.1.12

Silver, M. (1974). Procrastination. Centerpoint, 1, 49-54.

Sirios, F. M. (2004). Procrastination and Intentions to Perform Health Behaviors: The Role of Self-Efficacy and the Considerations of Future Consequences. Personality and Individual Differences, 37, 115-128. http://dx.doi.org/10.1016/j.paid.2003.08.005

Sirios, F. M. (2007). "I'll Look after My Health, Later”: A Replication and Extension of the Procrastination-Health Model with Community-Dwelling Adults. Personality and Individual Differences, 43, 15-26. http://dx.doi.org/10.1016/j.paid.2006.11.003

Sirios, F. M., Melia-Gordon, M. L., \& Pychyl, T. A. (2003). “I’ll Look after My Health, Later”: An Investigation of Procrastination and Health. Personality and Individual Differences, 35, 1167-1184. http://dx.doi.org/10.1016/S0191-8869(02)00326-4

Solomon, L. J., \& Rothblum, E. D. (1984). Academic Procrastination: Frequency and Cognitive-Behavioral Correlates. Journal of Counseling Psychology, 31, 503-509. http://dx.doi.org/10.1037/0022-0167.31.4.503

Stead, R., Shanahan, M. J., \& Neufeld, R. W. J. (2010). I'll Go to Therapy, Eventually: Procrastination, Stress and Mental Health. Personality and Individual Differences, 49, 175-180. http://dx.doi.org/10.1016/j.paid.2010.03.028

Steel, P. (2007). The Nature of Procrastination: A Meta-Analytic and Theoretical Review of Quintessential Self-Regulatory Failure. Psychological Bulletin, 133, 65-94. http://dx.doi.org/10.1037/0033-2909.133.1.65 
Steel, P. (2010). Arousal, Avoidant and Decisional Procrastinators: Do They Exist? Personality and Individual Differences, 48, 926-934. http://dx.doi.org/10.1016/j.paid.2010.02.025

Steel, P. (2012). The Procrastination Equation. Edinburgh: Pearson Education Ltd.

Steel, P., \& König, C. J. (2006). Integrating Theories of Motivation. Academy of Management Review, 31, 889-913. http://dx.doi.org/10.5465/AMR.2006.22527462

Steel, P., Brothen, T., \& Wambach, C. (2001). Procrastination and Personality, Performance, and Mood. Personality and Individual Differences, 30, 95-106. http://dx.doi.org/10.1016/S0191-8869(00)00013-1

Stromer, R., McComas, J. J., \& Rehfeldt, R. A. (2000). Designing Interventions that Include Delayed Reinforcement: Implications of Recent Laboratory Research. Journal of Applied Behavior Analysis, 33, 359-371. http://dx.doi.org/10.1901/jaba.2000.33-359

Tice, D. M., \& Baumeister, R. F. (1997). Longitudinal Study of Procrastination, Performance, Stress and, Health: The Costs and Benefits of Dawdling. Psychological Science, 8, 454-458. http://dx.doi.org/10.1111/j.1467-9280.1997.tb00460.x

Treasure, J. (2004). Motivational Interviewing. Advances in Psychiatric Treatments, 10, 331-337. http://dx.doi.org/10.1192/apt.10.5.331

Tuckman, B. W. (1991). The Development and Concurrent Validity of the Procrastination Scale. Educational and Psychological Measurement, 51, 473-480. http://dx.doi.org/10.1177/0013164491512022

Tuckman, B., \& Schouwenburg, H. C. (2004). Behavioral Interventions for Reducing Procrastination among University Students. In H. C. Schouwenburg, C. H. Lay, T. A. Pychyl, \& J. R. Ferrari (Eds.), Counselling the Procrastinator in Academic Settings (pp. 91-103). Washington DC: American Psychological Association. http://dx.doi.org/10.1037/10808-007

Tversky, A., \& Kahneman, D. (1992). Advances in Prospect Theory: Cumulative Representation of Uncertainty. Journal of Risk and Uncertainty, 5, 297-323. http://dx.doi.org/10.1007/BF00122574

Uzun Ozer, B., Demir, A., \& Ferrari, J. R. (2013). Reducing Academic Procrastination through a Group Treatment Program: A Pilot Study. Journal of Rational-Emotive \& Cognitive-Behavior Therapy, 31, 127-135. http://dx.doi.org/10.1007/s10942-013-0165-0

van Eerde, W. (2000). Procrastination: Self-Regulation in Initiating Avserive Goals. Applied Psychology: An International Review, 49, 372-389. http://dx.doi.org/10.1111/1464-0597.00021

van Eerde, W. (2003). A Meta-Analytically Derived Nomological Network of Procrastination. Personality and Individual Differences, 35, 1401-1418. http://dx.doi.org/10.1016/S0191-8869(02)00358-6

van Essen, T., van den Heuvel, S., \& Ossebaard, M. (2004). A Student Course on Self-Management for Procrastinators. In H. C. Schouwenburg, C. H. Lay, T. A. Pychyl, \& J. R. Ferrari (Eds.), Counseling the Procrastinator in Academic Settings (pp. 59-73). Washington DC: American Psychological Association. http://dx.doi.org/10.1037/10808-005

van Horebeek, W., Michielsen, S., Neyskens, A., \& Depreeuw, E. (2004). A Cognitive-Behavioral Approach in Group Treatment of Procrastinators in an Academic Setting. In H. C. Schouwenburg, C. H. Lay, T. A. Pychyl, \& J. R. Ferrari (Eds.), Counseling the Procrastinator in Academic Settings (pp. 105-118). Washington DC: American Psychological Association. http://dx.doi.org/10.1037/10808-008

Vancouver, J. B., \& Day, D. V. (2005). Industrial and Organisation Research on Self-Regulation: From Constructs to Applications. Applied Psychology: An International Review, 54, 155-185. http://dx.doi.org/10.1111/j.1464-0597.2005.00202.x

Vancouver, J., More, K., \& Yoder, R. (2008). Self-Efficacy and Resource Allocation: Support for a Nonmonotonic, Discontinuous Model. Journal of Applied Psychology, 93, 35-47. http://dx.doi.org/10.1037/0021-9010.93.1.35

Virués-Ortega, J., \& Haynes, S. N. (2005). Functional Analysis in Behavior Therapy: Behavioral Foundations and Clinical Application. International Journal of Clinical and Health Psychology, 5, 567-587.

Vroom, V. H. (1964). Work and Motivation. New York: Wiley.

Yoman, J. (2008). A Primer on Functional Analysis. Cognitive and Behavioral Practice, 15, 325-340. http://dx.doi.org/10.1016/j.cbpra.2008.01.002

Ziesat, H. A., Rosenthal, T. L., \& White, G. M. (1978). Behavioral Self-Control in Treating Procrastination of Studying. Psychological Reports, 42, 59-69. http://dx.doi.org/10.2466/pr0.1978.42.1.59 
Scientific Research Publishing (SCIRP) is one of the largest Open Access journal publishers. It is currently publishing more than 200 open access, online, peer-reviewed journals covering a wide range of academic disciplines. SCIRP serves the worldwide academic communities and contributes to the progress and application of science with its publication.

Other selected journals from SCIRP are listed as below. Submit your manuscript to us via either submit@scirp.org or Online Submission Portal.
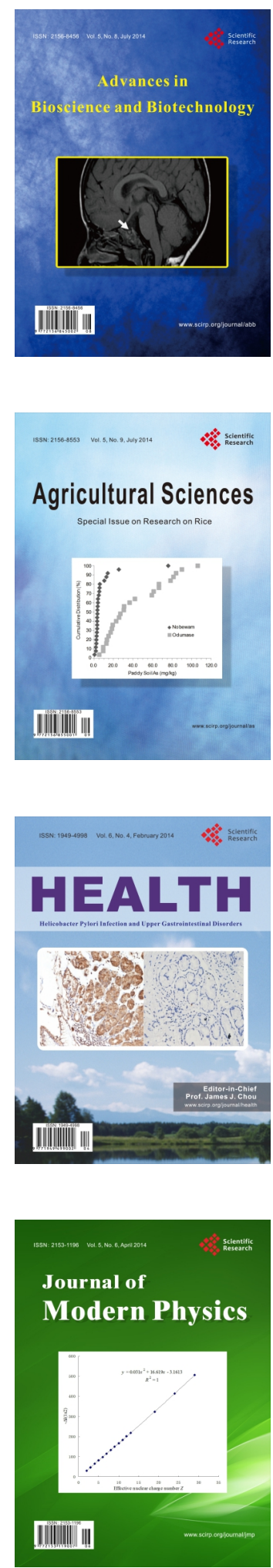
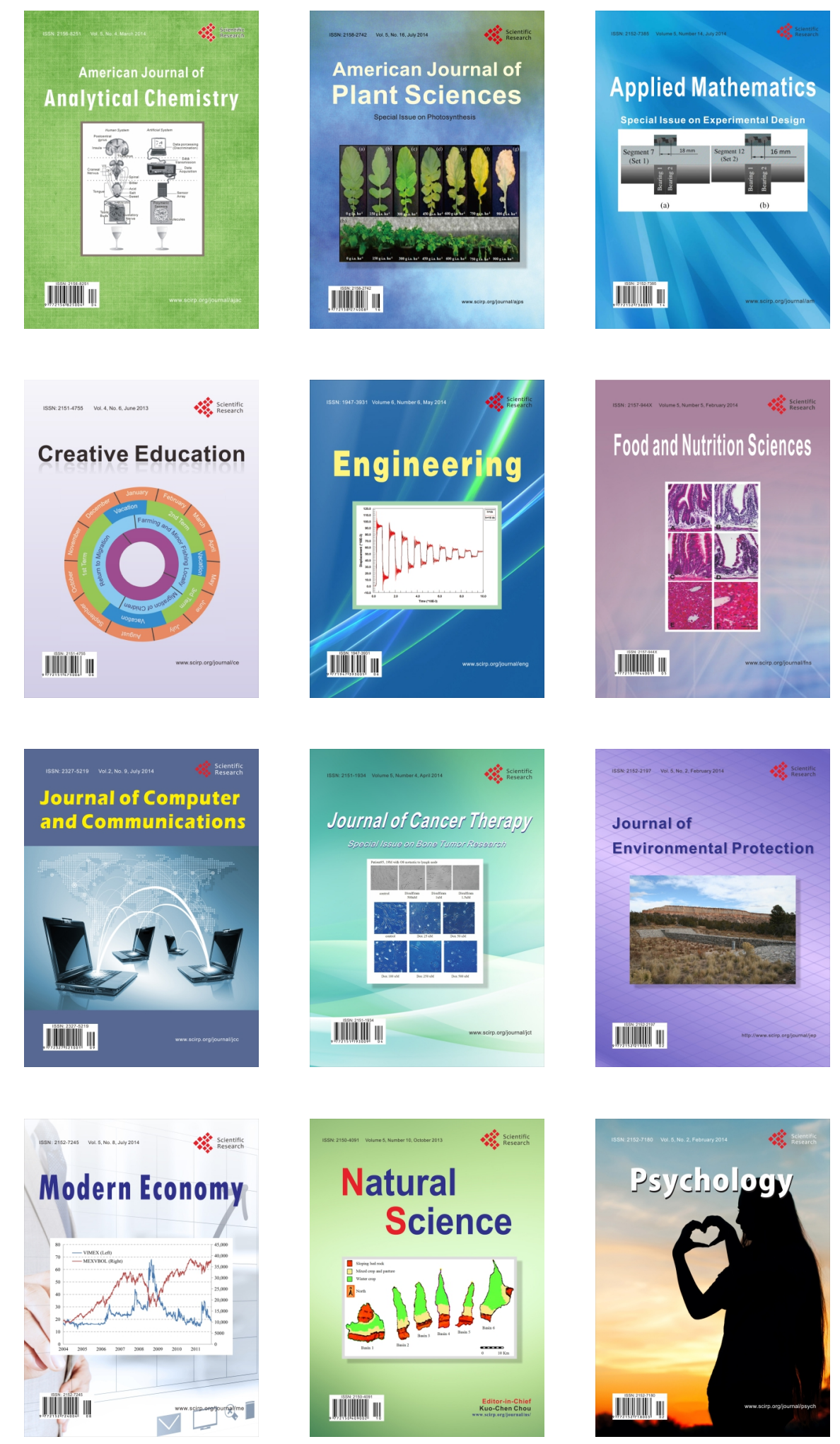